\title{
DETERMINE SIMULATION MODEL OF ELECTRONIC CONTROL SYSTEM FOR DIRECT INJECTION COMPRESSION COMBUSTION ENGINE
}

\author{
Haydar M. Razoqe ${ }^{1}$ \\ hyder_mohee@yahoo.com
}

\author{
Mahmoud A. Mashkour ${ }^{2}$ \\ 20087@uotechnology.edu.iq
}

1 Ministry of science and technology

2 Mechanical engineering Department, University of Technology Iraq

\begin{abstract}
The aim of this research is to determine a simulation of an electric control unit (ECU) for direct injection compression ignition combustion engine, in order to improve an engine performance and reduced fuel consumption. The simulation comprises thermodynamic model for determining engine parameters according to Spray Penetration Mixing Length, and imposes in Matlab and Simulink. This model allows closed loop control interferences with Arduino MEGA-2560 to manage amount of injected fuel and start of injection that, could be lead to obtain the optimum thermodynamic energy. The results of thermodynamic model show that, the engine parameters can be related linearly, and matching the other published researches on the same conditions and specifications. The results of (ECU) show synchronization between desired and output signals and appear more accuracy when compared with other methods.
\end{abstract}

Keywords: Electronic Control System; Compression Ignition Engine; Arduino Platform; Matlab / Simulink software; Thermodynamic Model of Compression Ignition Engine.

$$
\text { بناء نموذج محاكاة لمنظومة سيطرة الكترونية لمحركات الاحتراق بالضغط ذات الحقن }
$$

الخلاصة

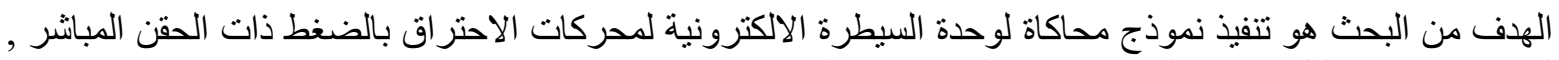

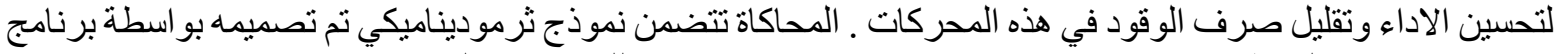

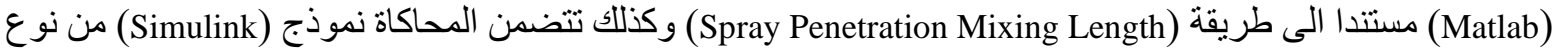
(Closed Loop)

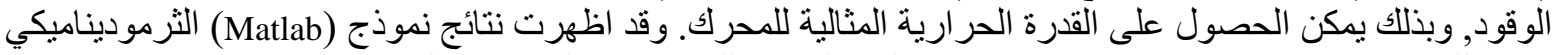

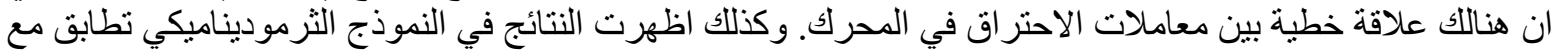

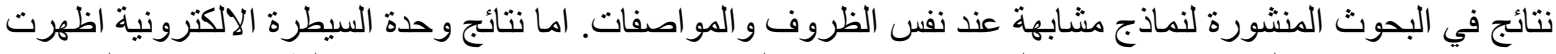

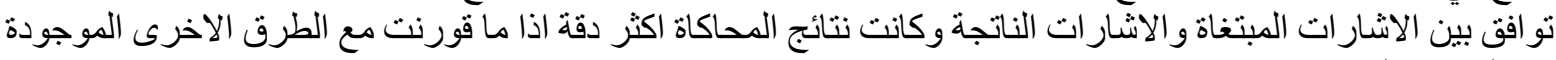
في البحوث المنشورة. 
NOMENCLTURE

\section{Latin Symbols}

A

B

$b$

$c$

$\mathrm{CN}$

$C p_{\text {fuel }}$

[CxHy]

$\frac{d[C x H y]}{d t}$

$\mathrm{dh}$

$d_{\text {orifice }}$

$\mathrm{Ea}$

$\mathrm{Ea} / \mathrm{T}$

f1

$H_{\text {air }}$

$h f g_{\text {fuel }}$

$H_{\text {fuel }}$

$H_{\text {prod }}$

$H x$

$k$

$\mathrm{L}$

$\grave{L}$

$\mathrm{m}$

$\mathrm{n}$

$\mathrm{Ru}$

$T_{a}$

$T_{\text {boil }}$

$T_{f}$

$T_{i n j}$

\section{Greek letters}

$\alpha$

$\beta$

$\rho_{\text {air }}$

$\rho_{\text {fuel }}$

$\rho$

$\theta$

$\phi_{L}$

\section{$\underline{\text { Subscripts }}$}

CA

ECU

E.O.I

\section{Description}

pre-exponential factor

energy ratio

correlation parameter

correlation parameter

cetin number

fuel specific heat at constant pressure $\left(\mathrm{kJ} \cdot \mathrm{kg}^{-1} \cdot \mathrm{K}^{-1}\right)$

fuel concentration $\left(\mathrm{gmol} / \mathrm{cm}^{3}\right)$

global reaction rate $\left(\right.$ gmol. $\left.\mathrm{cm}^{-3} \mathrm{~s}^{-1}\right)$

enthalpy change $(\mathrm{kJ} / \mathrm{kg})$

orifice diameter of injector $(\mathrm{m})$

activation energy $(\mathrm{kJ})$

Activation Temperature

constant parameter

air enthalpy $(\mathrm{kJ})$

fuel critical enthalpy $(\mathrm{kJ} / \mathrm{kg})$

liquid fuel enthalpy $(\mathrm{kJ})$

product gases enthalpy $(\mathrm{kJ})$

local enthalpy at point in cylinder $(\mathrm{kJ})$

correlation parameter

liquid length $(\mathrm{m})$

dimensionless factor of liquid length

imperial factor

imperial factor

universal gas constant $\left(\mathrm{kJ}^{\mathrm{kg}} \mathrm{kg}^{-1} \cdot \mathrm{K}^{-1}\right)$

air temperature $(\mathrm{K})$

fuel boiling temperature (K)

fuel temperature $(\mathrm{K})$

injection temperature of fuel (K)

correlation parameter

correlation parameter

air density $\left(\mathrm{kg} / \mathrm{m}^{3}\right)$

fuel density $\left(\mathrm{kg} / \mathrm{m}^{3}\right)$

density ratio

Spray spread angle (degree)

equivalence ratio at liquid length

\section{Description}

crank angle

electronic control unit

end of injection 
LCD

PWM

S.O.I liquid crystal display

pulse width modulation

Start of Injection

\section{INTRODUCTION}

Nowadays, the electronic engine control is an integral part of any work on the internal combustion engine. Development of internal combustion engine control system is oriented on exhaust emission, performance and fuel efficiency. The fuel efficiency can be improved by several method one of these method is by controlling the fuel injection duration and start of fuel injection to control the fuel consumption timing and load. That done, a Simulink control model is connected with a real system by programmable micro chipset open hardware platform such as Arduino. Data acquisition (DAQ) deal with taking signals from analogue potentiometers instead of engine parameters such as inlet manifold temperature, inlet manifold pressure, engine speed and fuel injection. (DAQ) are translated to Simulink control model by analogue input ports in Arduino chipset, in turn it calculates the control parameters of engines such as work done per cycle, start of injection and holes number in nozzle and then translates them to output device called liquid crystal displayer, which is a substitute for control signals to the engine. The general concept of the electronic control unit functionality, key timing requirement and period calculation within the cycle are set according to sense all critical engine operations parameters and calculate all the required engineering commands values, and the required output real time commands Breitzman (1985). Electronic control unite concentrates on the functionality of fuel metering(Vijay, Rao et al. (2010). By collecting data from various sensors, the electronic control controls the internal combustion engine speed by using electronic fuel injector actuator Vijay, Rao et al. (2010). The development of simulation based computer model of electronic control unit is very time and cost - effective in occupant safety development system and engine management system Vijay, Rao et al. (2010), Gonzalez, Florez et al. (2008). It is very interesting for internal combustion engine engineers to capitalize on the advantages of simulation as part of process of development, testing and optimization of advance control system Peyton Jones and Muske (2007).

The simulation control module allows processing of various sensors data such as engine speed inlet manifold temperature, injection temperature, inlet manifold pressure, cylinder wall temperature. this simulation could be used as tool for swift development and test models of electronic control unite in order to control the engine in laboratory for fuel economy and engine performance purposes and has been realized using Simulink, which is a component of Mathworks , MATLAB software Gonzalez, Florez et al. (2008), Vijay, Rao et al. (2010), Barber, Horra et al. (2013). Simulink model requires the ability to rapidly develop, test, and implement the algorithms necessary to control the combustion process as well as controls the interface hardware Triwiyatno, Sinuraya et al. (2015), Johnson, Roth et al. (2016). Look up tables are widely used in engine management strategies to characterize the nonlinear relationship between the input, such as speed and load and the desired output. These tables are therefore highly flexible, but this flexibility is achieved at the expense of the large number of parameters used to define the table Peyton Jones and Muske (2007).Integrating all of necessary functions into a simulation control model would require significant hardware and would limit the adaptability of electronic control to the evolving requirement for direct injection compression engine Han and Lee (2015), Johnson, Roth et al. (2016). It is preferable to have a flexible electronic control architecture that can support the addition, deletion and modification of sensors and actuators, and allow this change to be made rapidly. 
Oskam was investigated MATLAB simulation model for heat release by employing vibe parameters and the analysis of temperature - specific entropy techniques. Techniques were tested through simulations models, functioning as the selected 12SW28 benchmark engine, were used to analyze the pressure measurements collected from the Marinebedrijf. Oskam (2014). Peng Qi, et al. were proposed quasi-dimensional model for compression ignition engine by applying MATLAB Simulink, based on the phase divided spray mixing model. They used hardware model-in the- loop simulation system to satisfy the performance demand of a diesel engine model. Qi, Feng et al. (2010). Gonzalez, et al. were carried out an engine control unit for an Otto cycle with electrical fuel injection, they were used Simulink and State flow, which are components of MATLAB software. Gonzalez, Florez et al. (2008). Lanský was achieved MATLAB-Simulink model for cylinder, the model was involved the cylinder thermodynamic, geometry, fuel mass flow, and combustion process descriptions, as well as was determined ECU for the engine output torque control Lanský (2008).

The following aims can be drawn to study:

1- Achieving a thermodynamic model of compression ignition combustion engine to describe the thermodynamic behaviours of combustion by using MATLAB platform.

2- Developing an electronic control unit model, to control and manage the engine load and the time of injection by using Simulink platform and Arduino microchip.

\section{MATERIAL AND METHOD}

\section{Simulink / MATLAB and Arduino}

Arduino is an open source programmable hardware, utilized to communicate simulation model with the real world, furthermore MATLAB and Simulink have been consolidated in engineering and in academic world as a design and development tool. So the ability of linking Arduino and MATLAB Simulink is an interesting matter Breitzman (1985). Communication Arduino with MATLAB Simulink consists of installing the support target for Simulink that comes with MATLAB versions and requires Windows operating system. The algorithm has been designed in MATLAB -Simulink environment. Analogue input is a block measure the voltage of an analogue output pin in Arduino platform as shown in figure (1), it outputs the voltage as digital value, its resolution (0-1023), in this project transforms the signals from potentiometer to the Simulink model. This Simulink block allows setting the sample rate to theoretically a value as low as $0.000001 \mathrm{~s}$, in most of computers such value is sure to frozen. A logical value is $0.02 \mathrm{~s}$ sample time; lower values mean a change in scale time axis. Data type conversion block its function converts the signal, from Analogue input, to desired data type, the data type shown in figure (1).Look up table block in this project, 1-D Look up table and 4D Look up table have been used, each type has different functions from other, the first one calibrates the data from Analogue input block and data type conversion block to the desired parameters data as shown in figure (1). However, the other one is to select the required data according to the break points in this project, four break points mass flow rate, engine speed, pressure, and temperature of entire air, as shown in figure(1). S-Function Builder block integrates $\mathrm{C}++$ code to build an $\mathrm{S}$-function from specifications and $\mathrm{C}$ code that you supply. The S-Function Builder also serves as a wrapper for the generated S-function in models that use the S-function. In this project the S-Function Builder is used to build simple C MEX Sfunctions. The function is translate the output data to output display device, Liquid Crystal displayer, which connected to the Arduino platform, the S-Function block is shown in figure (1) Arduino 2015, Baykara, Kutlar et al. (2017). 


\section{Simulink Model}

The Simulink model consists of two parts, manual system control and Automatic System Control, as shown in Fig. (3). The algorithm of manual system has three main elements, as shown in flow chart in Fig. (2). In the first element, the input data has been acquired from the real world as signals usually from sensors but in this project, potentiometers would be alternative of sensors, the active block for this function is the input analogue block. The second element is processing the acquire data and results the effective control data, such as maximum energy per cycle and start of injection. This process is done by look up table block, which is tabulated with the data, which are pre-calculated by thermodynamic model. The last element outputs the desired data to the real word in form of digital signals by S-Function Builder block which translates the signals to a display device. The development of the programmable platform model allows to support the researches in engines at education internal engine laboratory, based on thermodynamic model which will describe later Raeie, Emami et al. (2014).

\section{Automatic System Control}

Automatic system differs from manual in two things the first one there is reference parameters such as energy, the other one is a feedback sub model, which is shown in Fig (4). The feedback block receives the reference signal and other input signals and treats them, as shown in flow chart in Fig. (5) set of desired energy per cycle is tabulated in look up table, as shown in Fig. (3). The dependent parameters are intake manifold pressure, intake manifold temperature, engine speed, and reference input signals. These parameters are corresponding break points, the output parameter is corresponding the reference value, which is input to feedback sub-model block, as shown in Fig (4). At a specified value of energy, reference point or desired point, this signal is remaining constant as comparative signal in closed loop, as shown in Fig (4). The closed loop involves internal logical operation, the operation increases or decreases the mass flow rate of fuel depending on the comparative signal, so the iteration of procedure, which is shown in flow chart in Fig. (5), has been processed until the desired energy output reaches to energy reference. The feedback sub-model sends two output signals, energy output and mass flow rate at that energy, then the resulted signal of mass flow produces start of injection crank angle by using another look up table at specified engine velocity, pressure and temperature of intake manifold air, as shown in flow chart in Fig. (5). The data of work per cycle and start of injection are arranged in look up tables versus fuel mass flow rate at different engine speeds. The arrangement data are shown in Fig(6) and Fig (7) respectively. In look up tables, the data selection at break points is done according to a linear interpolation fitting in four dimensions. The statistic measure of closing data to the fitted regression line is indicated in Table 1), which evaluates the regression - square factor of energy per cycle versus fuel mass flow rate at different engine speeds, pressures, and temperatures of entire air Triwiyatno, Sinuraya et al. (2015), Zulkifli, Yusof et al. (2015), Slepicka and Koch (2016), Baykara, Kutlar et al. (2017).

\section{Thermodynamic MATLAB Model}

A mathematical model for single cylinder, four stroke, and direct injection diesel engine is developed by taking into consideration the engine thermodynamics properties with moving parts dynamic and fuel injection. The mathematical formulation of the model has been coded in the platform, which is used for interconnected the various engine sub-models deals with fuel injection and its effects on penetration liquid length, vaporization of liquid phase and fuel mixing with air, in this sub-model maximum penetration length distance of liquid phase as 
well as vaporized fuel and mixing air through penetration length of fuel during injection pulse has been calculated as follows Thring and Newby (1953), El Wakil, Myers et al. (1956), Bracco (1985), Kuo (1986), Lefebvre (1989), Siebers (1999), Morgan, Wray et al. (2001).

$$
\begin{aligned}
& L=k \cdot d_{\text {orifice }} \cdot \rho^{\alpha} \cdot B^{\beta} \\
& B=\frac{C p_{\text {fuel }} \cdot\left(T_{\text {boil }}-T_{\text {inj }}\right)+h f g_{\text {fuel }}}{d h} \\
& \rho=\frac{\rho_{\text {fuel }}}{\rho_{\text {air }}} \\
& \theta=c \cdot\left[\left(\frac{1}{\partial}\right)^{0.19}-0.0043 \cdot \sqrt{\rho}\right] \\
& L=b \cdot \sqrt{\left[\frac{2}{B(T a, \rho a, T f)}\right]^{2}-1} \\
& \phi_{L}=\frac{\sqrt{1+16 \cdot(L)^{2}}-1}{2}
\end{aligned}
$$

Where $\mathrm{L}$ is liquid length, $d_{\text {orifice }}$ is orifice diameter of injector, $k, \alpha, \beta, c, b$ are correlation parameters, $\rho^{\prime}$ is density ratio, B is energy ratio, $\rho_{\text {fuel }}$ is fuel density, $\rho_{\text {air }}$ is air density, $\theta$ is Spray spread angle, $T_{\text {boil }}$ is fuel boiling temperature, $T_{i n j}$ is injection temperature of fuel, $C p_{\text {fule }}$ is specific heat at constant pressure, $h f_{g_{\text {fuel }}}$ is fuel critical enthalpy, $d h$ is enthalpy change, $L^{z}$ is dimensionless factor of liquid length, $\emptyset_{L}$ is equivalence ratio at liquid length, $T_{a}$ is air temperature, $T_{f}$ is fuel temperature. The sub-model accounts the effect of injector, fuel properties and thermodynamic conditions, accompanying that several processes as adiabatic compression, adiabatic extension, premixed combustion, heat release, and heat transfer as follows Watson, Pilley et al. (1980), Nishida and Hiroyasu 1989, Turns 1996, Jung and Assanis (2001), Ferguson and Kirkpatrick (2015), Watson, Pilley et al. (1980), Nishida and Hiroyasu (1989), Turns (1996), Jung and Assanis (2001), Ferguson and Kirkpatrick (2015).

$$
\begin{aligned}
& E a=\frac{f 1}{(C N+25)} \\
& \frac{d[C x H y]}{d t}=-A \cdot e^{\left(\frac{-E a}{R u \cdot T}\right)} \cdot d[C x H y]^{m} \cdot[O 2]^{n} \\
& \tau=A 2 \cdot P^{a 1} \cdot e^{\left(\frac{a 3}{T}\right)}
\end{aligned}
$$

Where $E a$ is activation energy, $f 1$ is constant parameter equal $618840, C N$ is cetane number, $A$ is Pre-exponential factor, $E a / T$ is Activation Temperature, $m, n$ are imperial factor, $R u$ is universal gas constant, $d[C x H y] / d t$ is global reaction rate, $C x H y$ is fuel concentration, $\tau$ is ignition delay, $A 2$ is constant equal $3.45, a 1$ is constant equal -1.02 , a3 is constant equal 2100. Isentropic sub-model calculates the cylinder conditions throughout compression and expansion stroke, during compression process the composition is air in cylinder, during expansion processes is air and ideal products gases are calculated based on the overall equivalence ratio, the change in thermodynamic properties during compression an expansion process based on isentropic processes. The premixed combustion process calculated in adiabatic sup-model which calculate the chemical reaction equilibrium and adiabatic flame temperature. Main sub-models contained empirical thermodynamic relations to calculate heat transfer, ignition delay and heat release solved numerically. The model calculates many 
parameter such as work done per cycle, temperature, pressure, heat transfer, heat release distribution with crank angle numerically at several input parameters such as temperature and pressure at intake manifold, engine dimensions, injector specifications, cylinder wall temperature, compression ratio, mass flow rate of fuel, and fuel properties. The combustion model theory divides the combustion chamber into five zone liquid fuel, vapor fuel, rich products, diffusion flame, and surrounding gasses the properties of these zones such as volume, enthalpy, and temperature controlled by several parameters such as intake pressure and temperature, engine speed, fuel quality, injector dimensions, compression ratio, ignition delay, fuel properties, and engine parameters Heywood (1988). So it's extremely necessary develop model coordinate the parameters in zones applying first law of thermodynamic and energy balance between these zones according to $\mathrm{Eq} \mathrm{10,} \mathrm{the} \mathrm{temperature} \mathrm{variation} \mathrm{across} \mathrm{(fuel}$ vapor zone) can be calculated using an energy balance illustrates the energy balance at a distance, $\mathrm{x}$ as shown in figure (8).

$$
H x=\text { Hfuel }+ \text { Hair }+ \text { Hprod }
$$

\section{The Hardware System}

Control unit system consist of elements input unit, microprocessor unit and output unite. As mentioned before, the input unit consists of a collection of potentiometers, translates the signal to the analogue input in Arduino mega 2560, which is corresponding the microprocessor and interface with Simulink model in personal computer that in turn translates the data signal to the crystal liquid displayer by pulse width modulation (PWM) in the Arduino platform the scheme of control unit system, as shown in Fig. (5). Potentiometer sends the signals in analogue input in Arduino mega 2560 as voltage calibrated as value signal in microprocessor and Simulink model in input analogue block with (0-1023) resolution. After the proceeding of the required process, the output translates from pulse width modulation to liquid crystal displayer (LCD), as shown in Fig. (9). The output data are translated to (PWM) by $\mathrm{S}$-Function Builder block, which is coded in $\mathrm{C}++$ language to receive the input data and translate it to (PWM). By constructing compiler file able to modify and compile with files contain the orders and codes of Arduino LCD published in math work in MATLAB version called "LiquidCrystal.h" and "LiquidCrystal.cpp", the results data would be shown in Liquid Crystal Displayer as shown in Fig. (17) and Fig. (18). Translate the Simulink model from the computer to the microprocessor in Arduino mega 2560 by USB cable data is shown in figure (10). and figure (11) .

\section{RESULTS AND DISSECTION}

The results Based on applying ramp step signal as alternative of energy reference input analogue, the results shown in scope block in the synchronization between input signal and output signal of energy with time. The mean error of this unit is less than $(1 \%)$ and the maximum difference is between desired and output energy is $0.24 \mathrm{~kJ}$, these data is considered better than the data in Lanský (2008), where the mean error was about 13\% and maximum difference between output and desired data is about $30 \mathrm{~N} . \mathrm{m}$. The results of manual system control are appeared in Fig. (2) and Fig. (13), the appeared input data are mass flow rate of fuel (Mfuel) and engine speed (R.P.M), and output data are work per cycle (energy) and start of injection angle (S.O.I), while the results of automatic control system are appeared in Fig. (18), the appeared input data are reference work per cycle (E_SET) and engine speed (R.P.M), and the appeared output data are the output work (E_OUT) and start of injection angle (S.O.I) during transit condition. The results of mathematical model shown in Fig. (14), and Figure (16). Show the maximum penetration length of fuel the zone which have yellow colour is liquid phase fuel, the next zone is vaporizing, so the next is premixed zone, and the 
last one is rich product zone, the results of penetration spray are matched with results from which they were taken from Siebers (1999). Fig. (15) show the distribution of temperature with crank angle and Fig. (14) show pressure distribution with crank angle, the results of simulation model for pressure and distribution with crank angle are similar to the results and trend behaviour in Egüz (2013).

\section{CONCLUSIONS}

1- Thermodynamic model has been applied in MATLAB. Which allows to determine the development of the cylinder pressure and temperature with variation of crank angle. The results and trend behaviour of simulation model are similar to that in published researches.

2- The engine parameters such as, energy per cycle, start of injection, engine speed, intake air pressure and temperature are related with linear function, and can be arranged in look up table.

3- The simulation of (ECU) comprises Simulink closed loop model interference with programmable microcontroller to manage amount of injected fuel and start of injection, in turn obtained the optimum thermodynamic energy. The processing of input signals are carried out by interpolating values in look up tables, the approaching of output signal to desired signal is obtained by applying feedback model. The results of ECU shows synchronization between desired and output signals with mean error less than one (1\%) and maximum difference about $0.24 \mathrm{~kJ}$.

Table 1:Regression- Square Factor Evaluation of Energy Versus Fuel Mass Flow Rate

\begin{tabular}{|c|c|c|c|}
\hline $\begin{array}{l}\text { Engine } \\
\text { Velocity }\end{array}$ & $\mathrm{P}(\mathrm{kPa})$ & $\mathrm{T}(\mathrm{K})$ & $R^{2}$ \\
\hline \multirow[t]{6}{*}{1200} & \multirow[t]{3}{*}{192} & 400 & .9772 \\
\hline & & 425 & .9891 \\
\hline & & 450 & .9927 \\
\hline & \multirow[t]{3}{*}{250} & 400 & .9554 \\
\hline & & 425 & .9529 \\
\hline & & 450 & .9824 \\
\hline \multirow[t]{6}{*}{1500} & \multirow[t]{3}{*}{192} & 400 & .9909 \\
\hline & & 425 & .9916 \\
\hline & & 450 & .9939 \\
\hline & \multirow[t]{3}{*}{250} & 400 & .9916 \\
\hline & & 425 & .9934 \\
\hline & & 450 & .9943 \\
\hline \multirow[t]{6}{*}{1800} & \multirow[t]{3}{*}{192} & 400 & .9762 \\
\hline & & 425 & .9816 \\
\hline & & 450 & .9799 \\
\hline & \multirow[t]{3}{*}{250} & 400 & .9943 \\
\hline & & 425 & .9826 \\
\hline & & 450 & .9847 \\
\hline
\end{tabular}




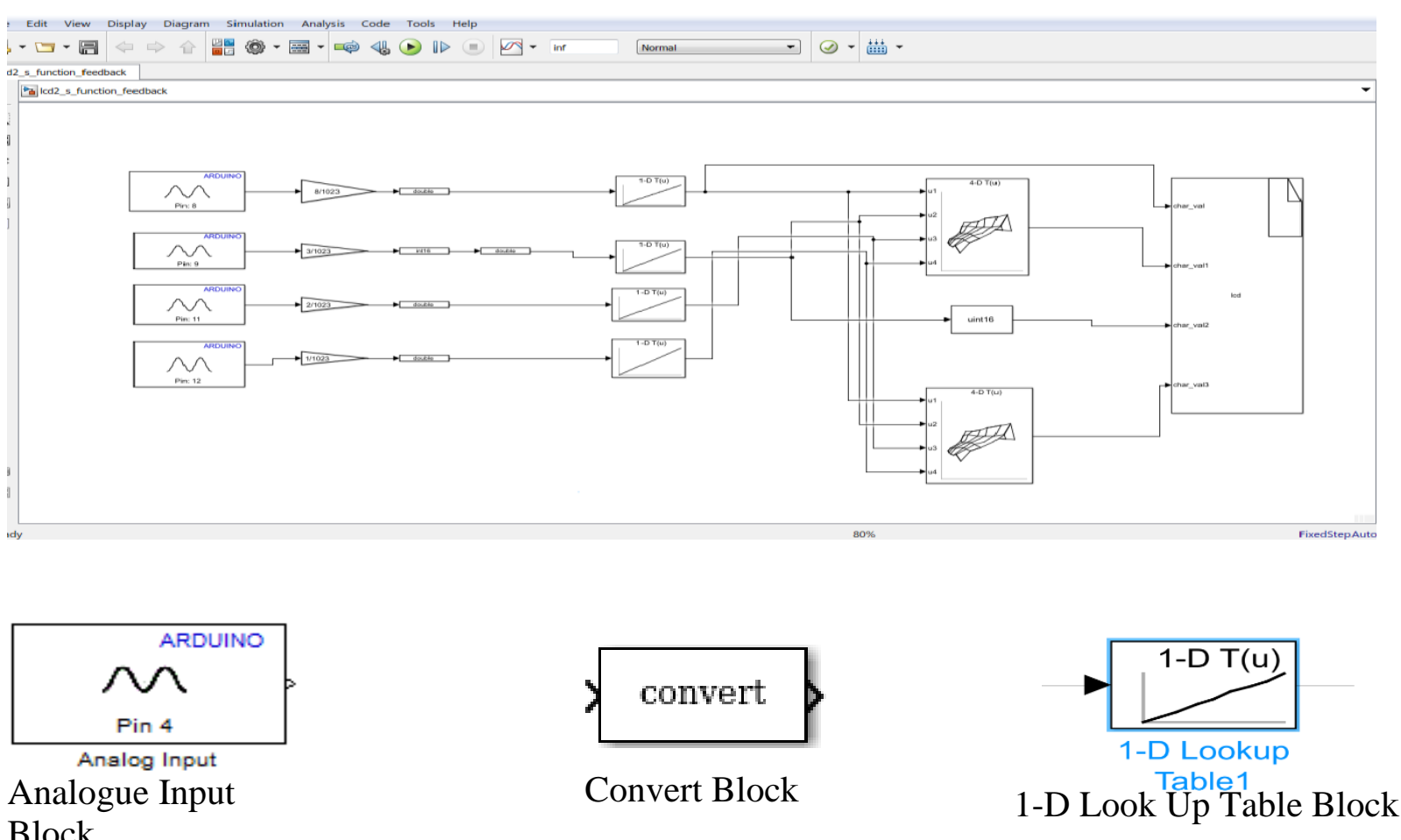

Block

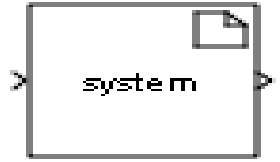

S- Function Builder Block

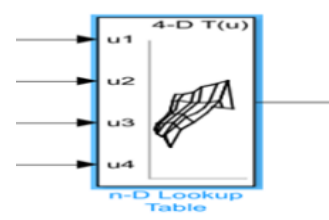

n-D Look Up Table Block

Fig. (1) : Manual Control System Model

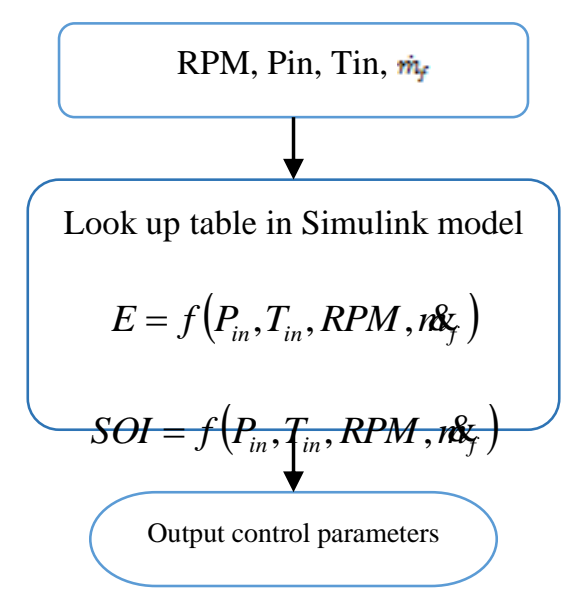

Fig. (2): Manual System Algorithm 
Haydar M. Razoqe The Iraqi Journal For Mechanical And Material Engineering, Vol.20, No3,Sept. 2020

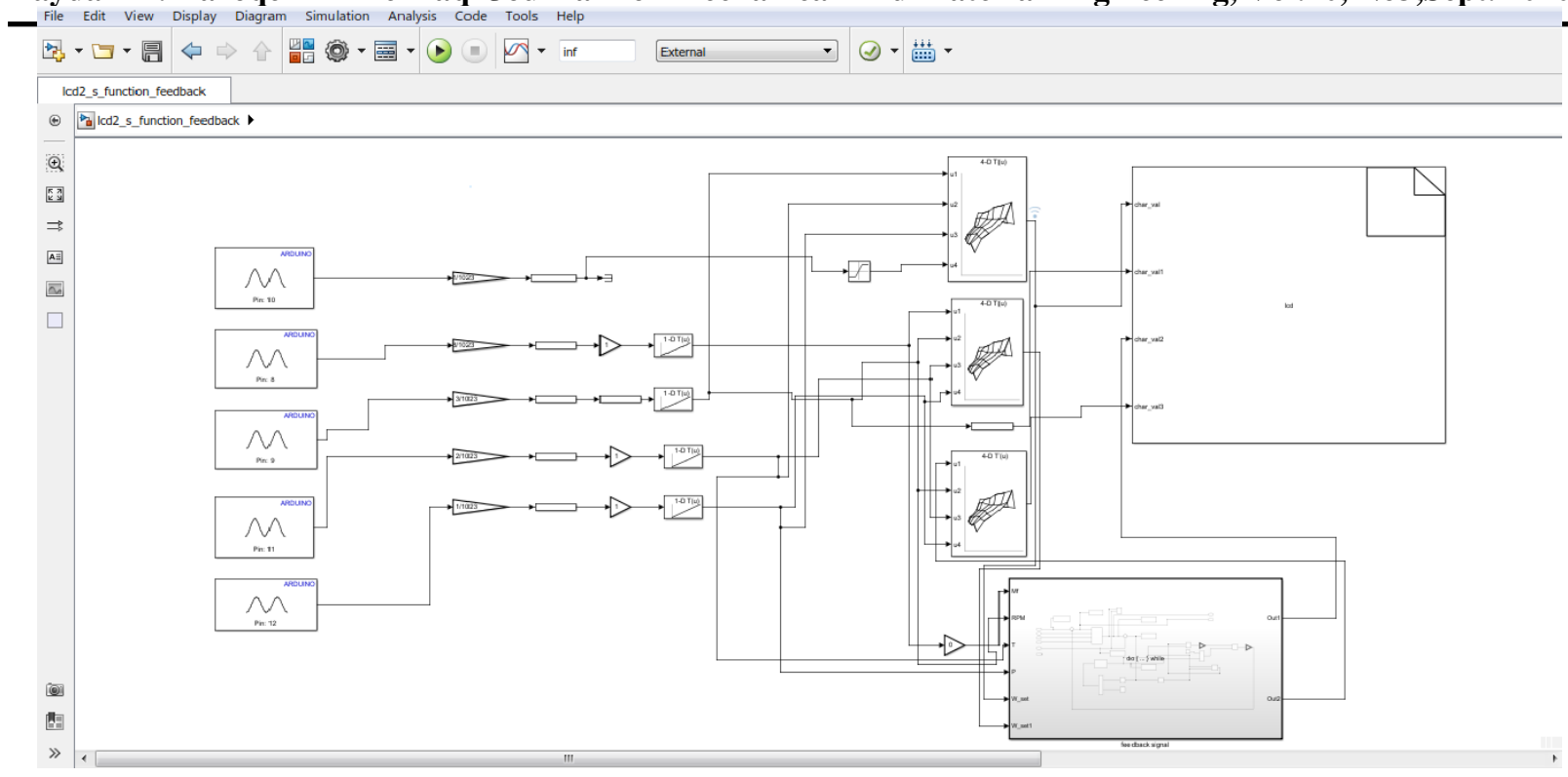

Fig. (3): Automatic Control System

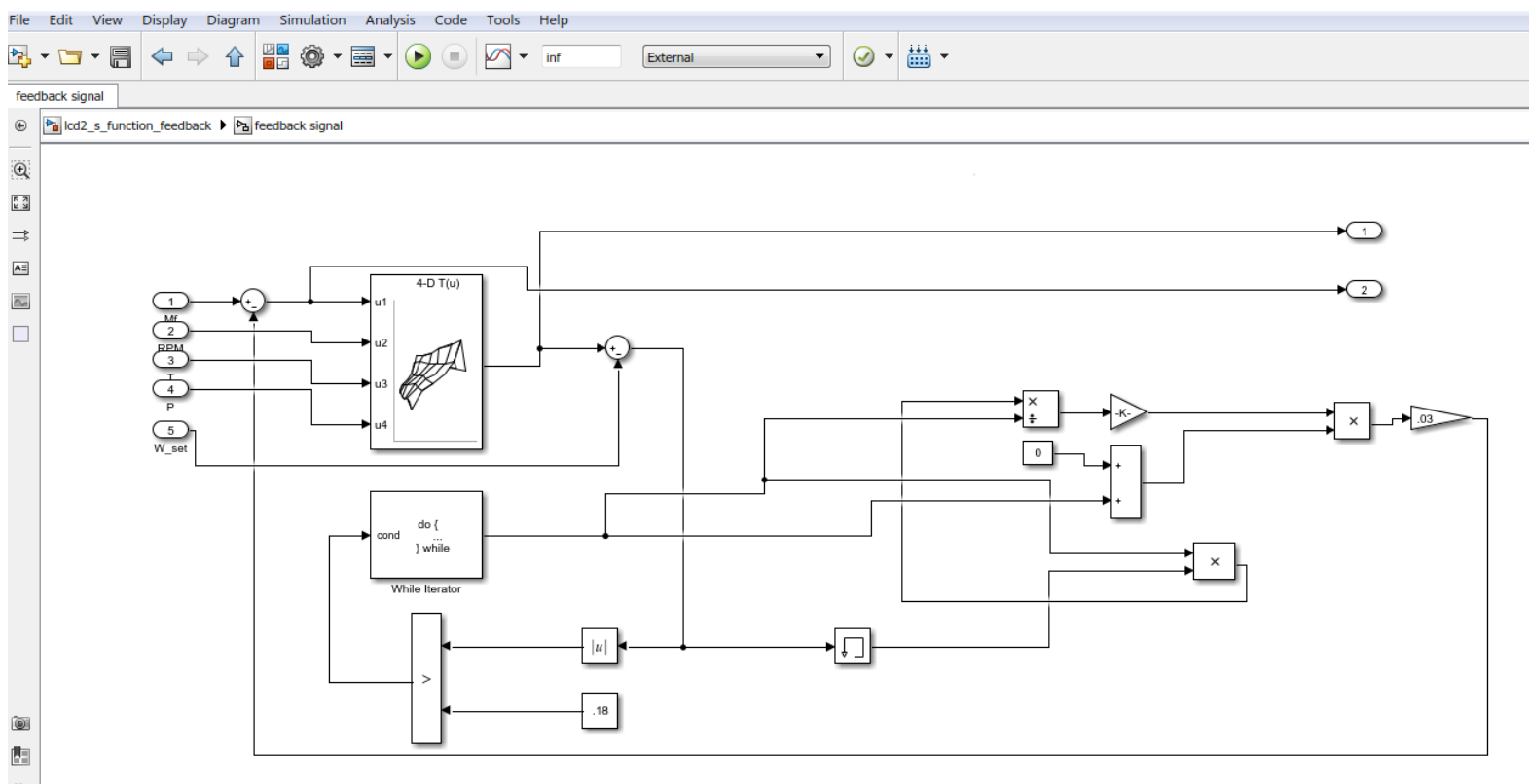

Fig. (4): Feedback Model 


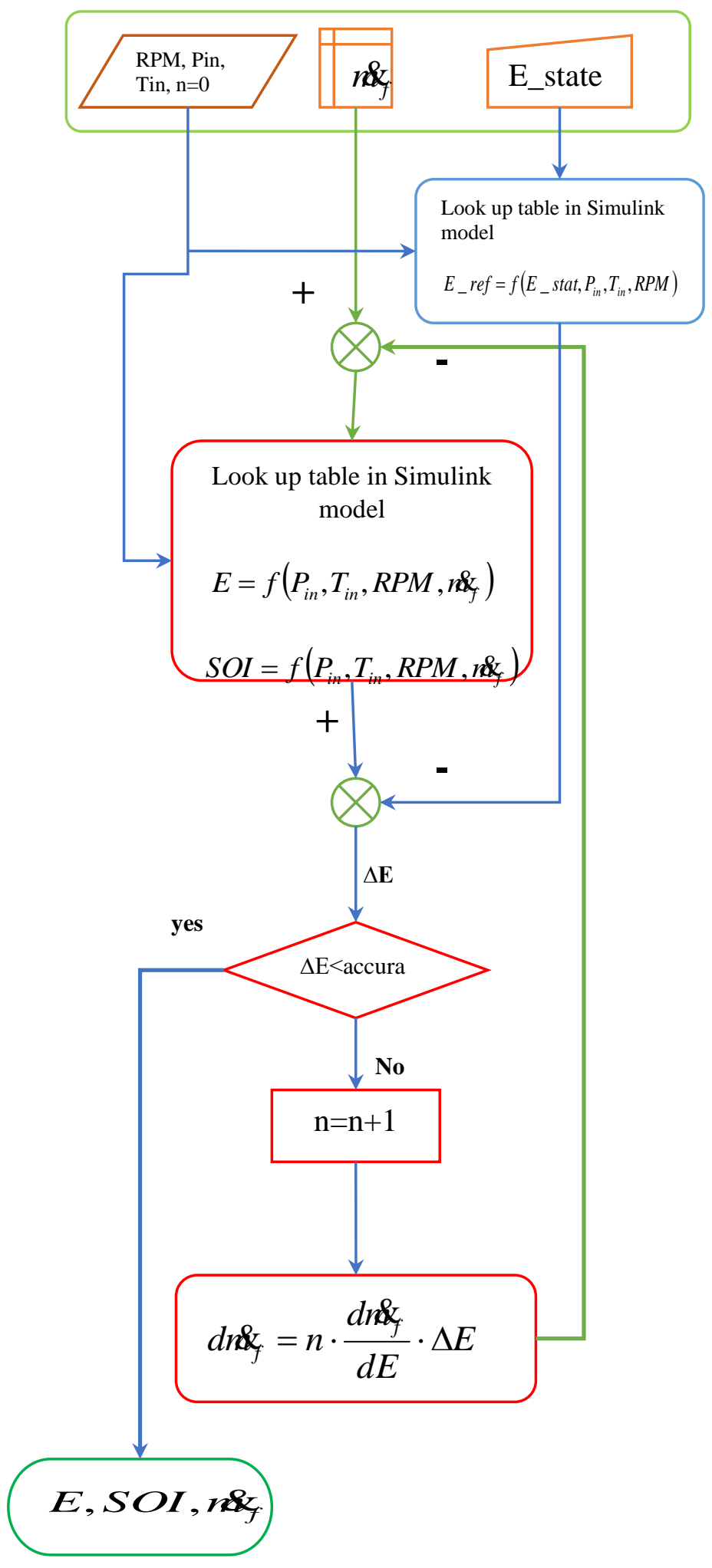

Fig. (5): Automatic Control System Scheme 

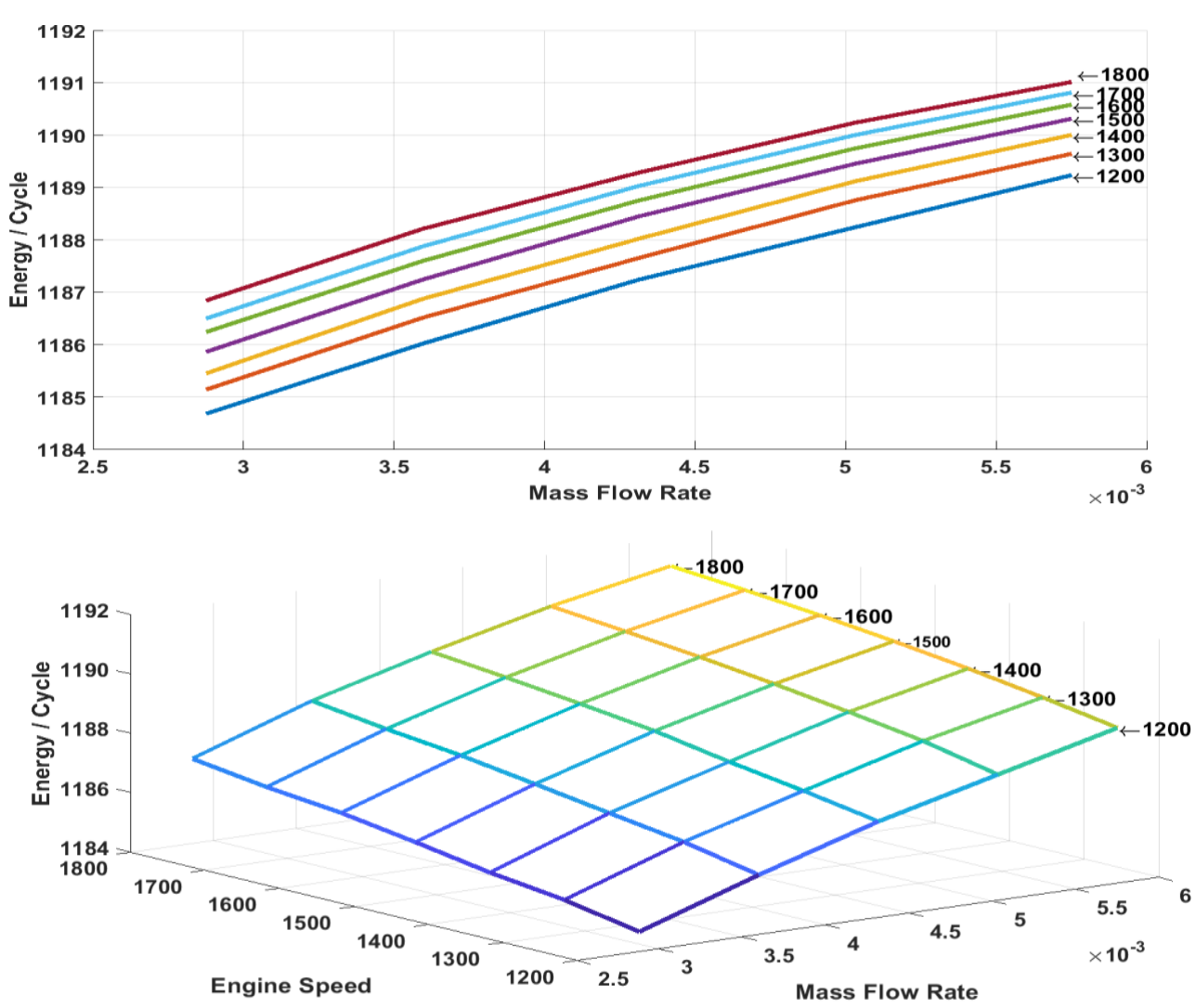

Fig( 6): Energy/Cycle Verses Mass Flow Rate Data
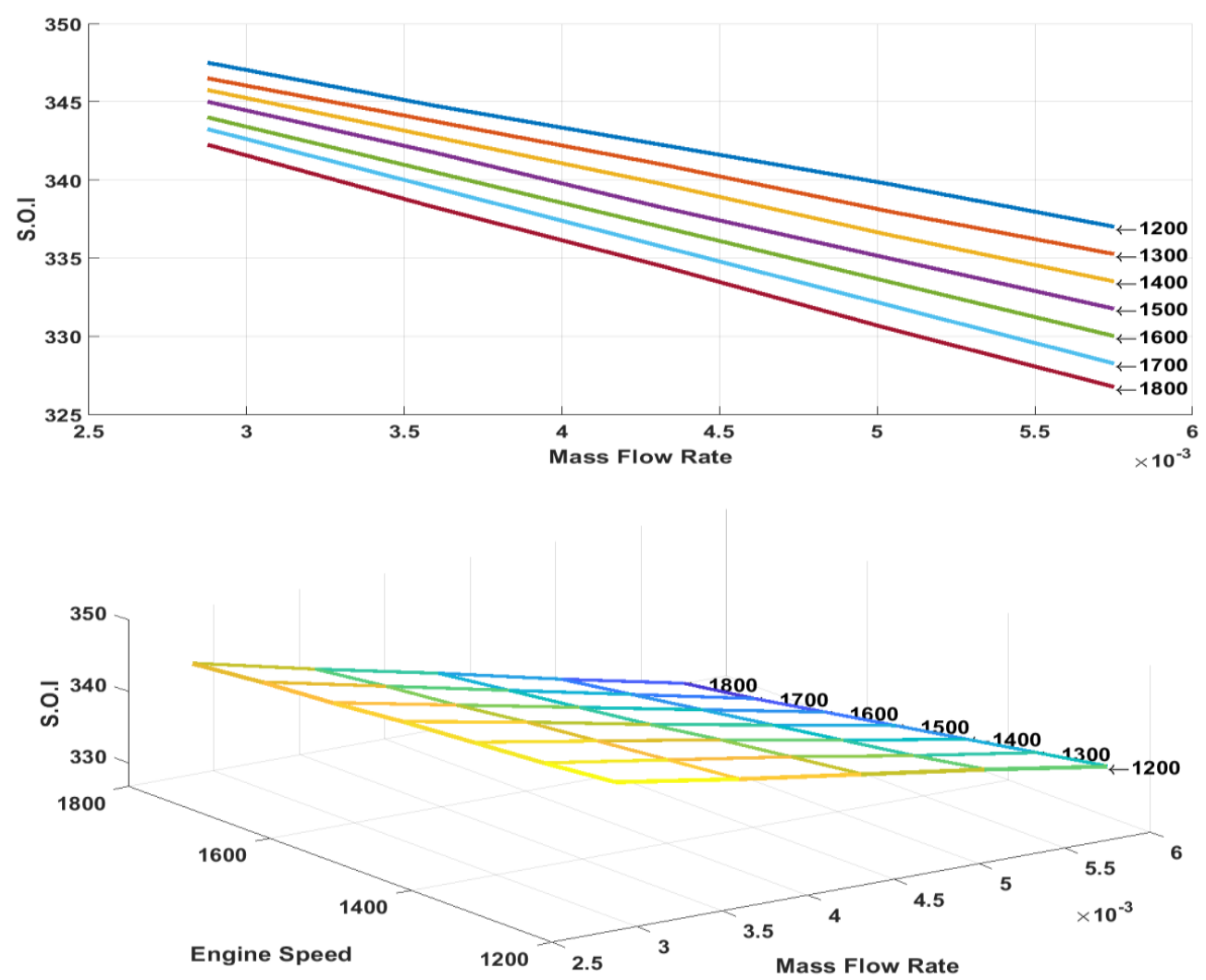

Fig. (7): Start of Injection Verses Mass Flow Rate Data 


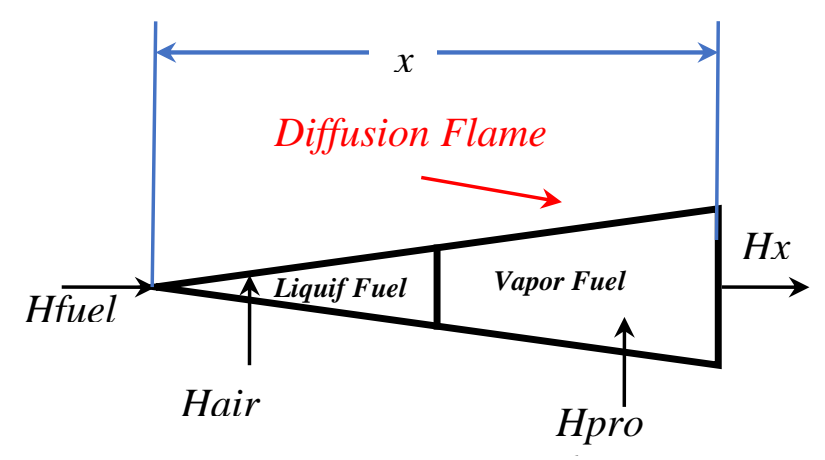

Fig. (8): Zones Energy Balance Scheme

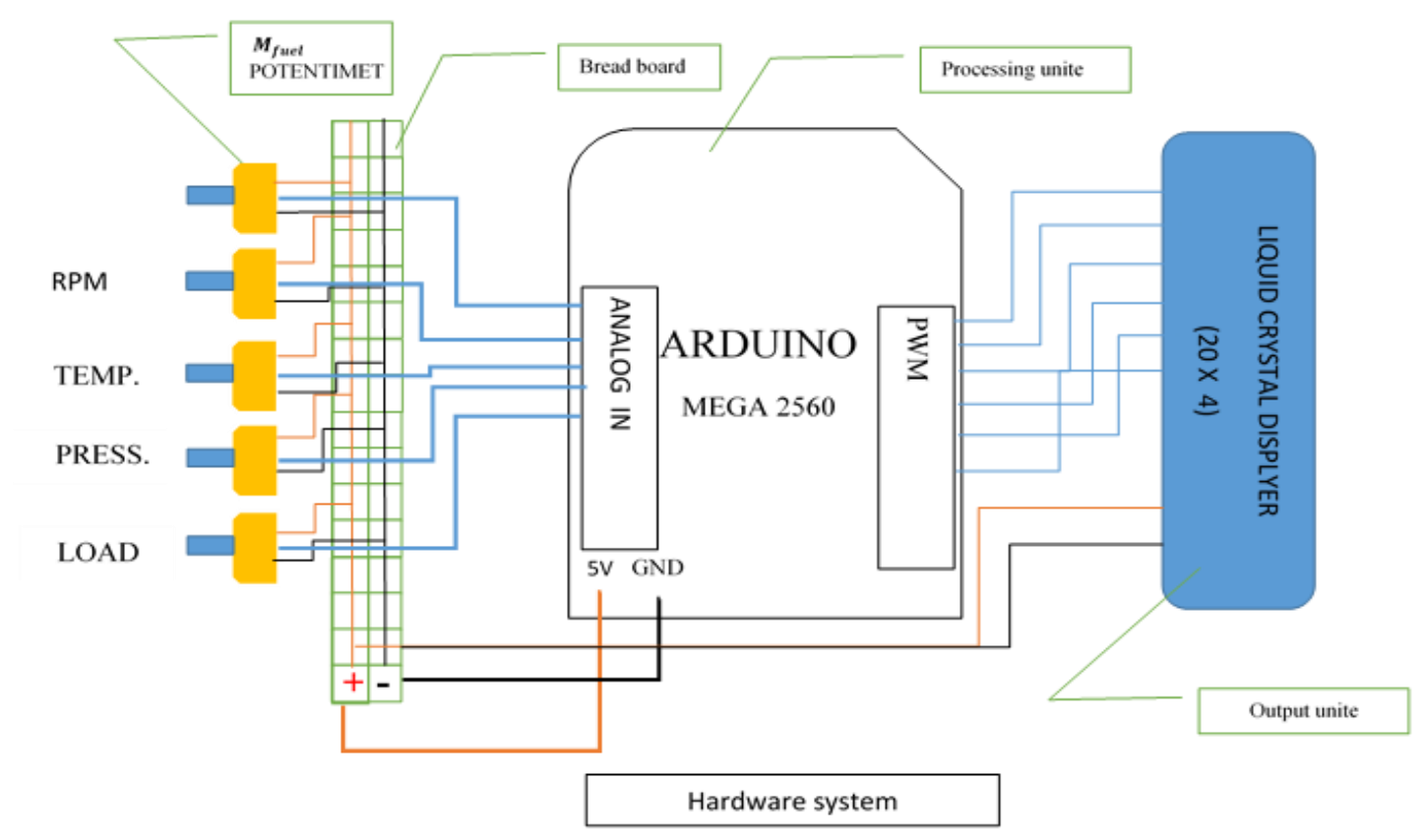

Fig. (9): Control System Unit Scheme

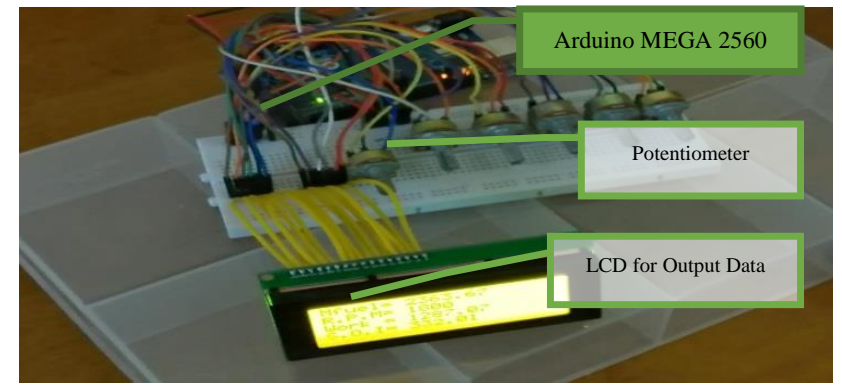

Fig. (10): Hardware Assembly of Control System Unit

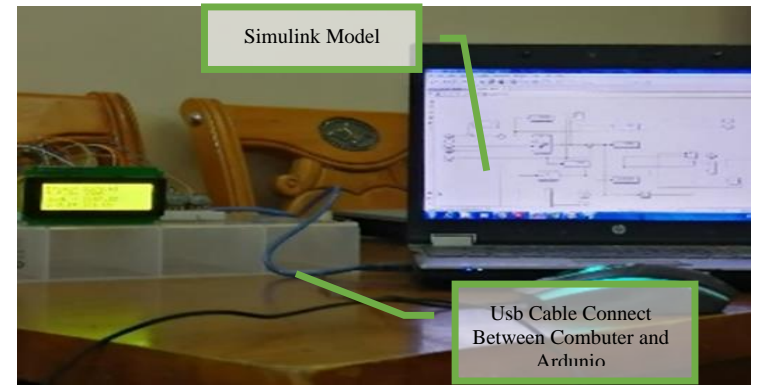

Fig. (11): Hardware and Software of Control System 


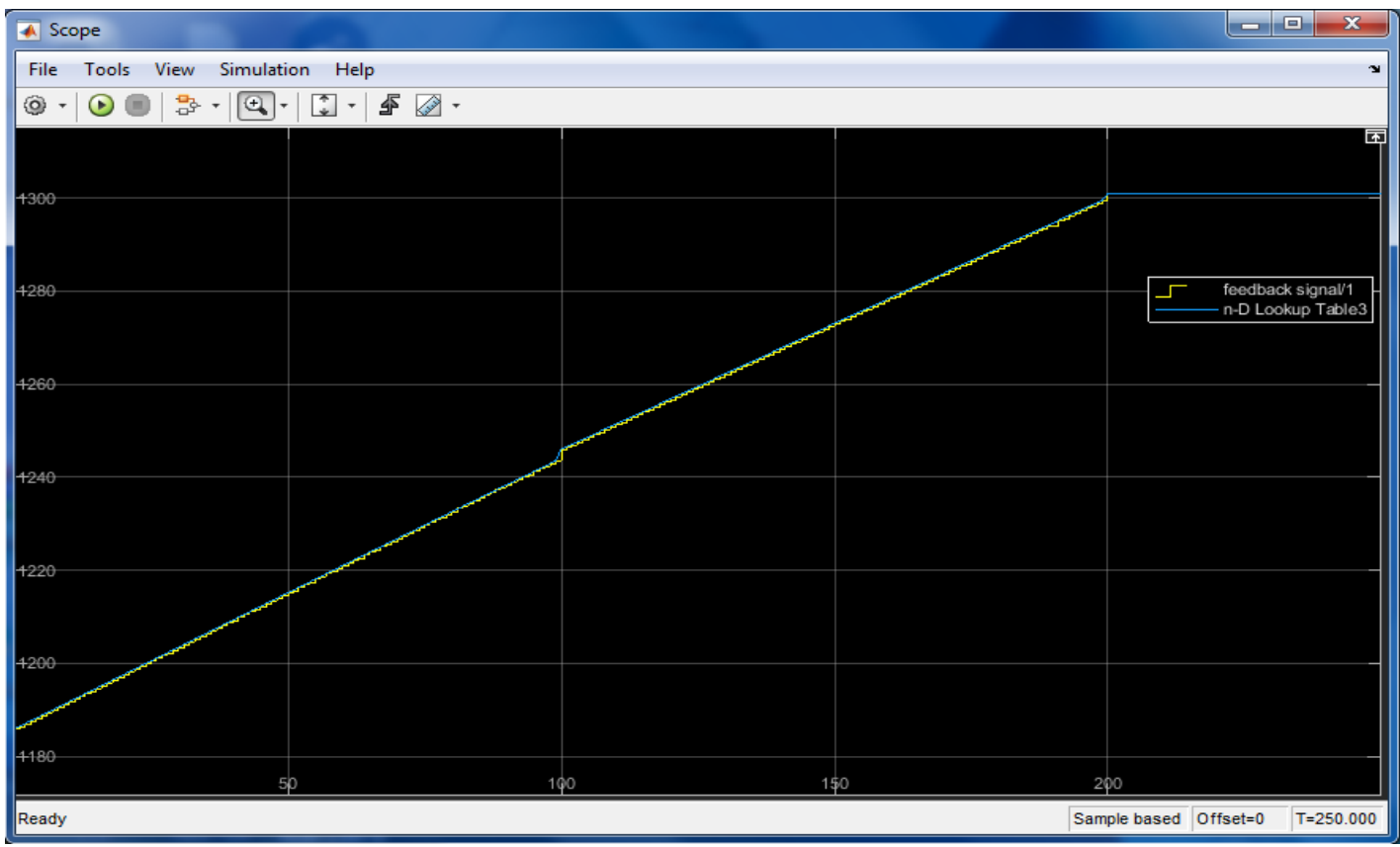

Fig. (12): Continue Input and Discrete Output in the Scope

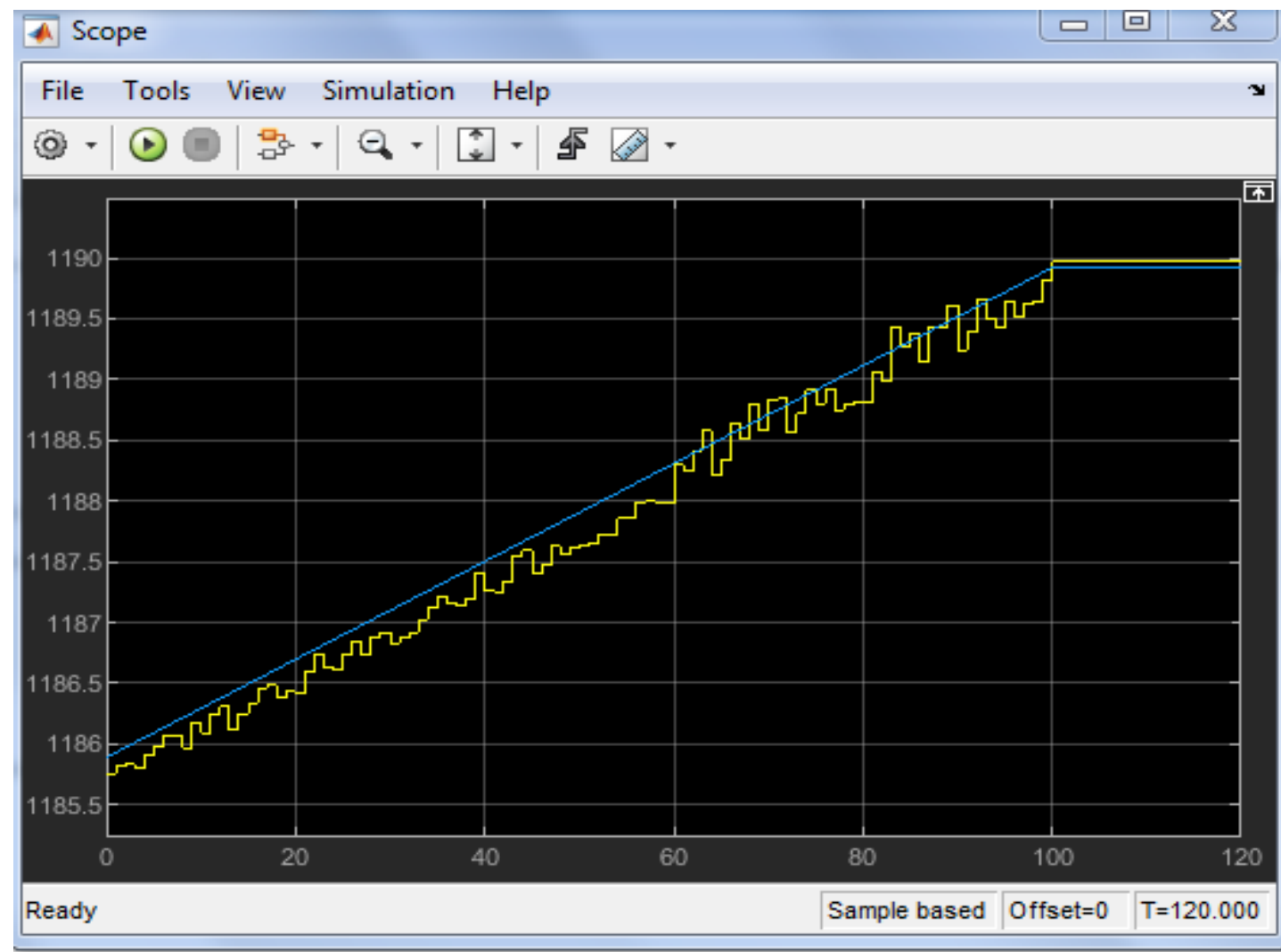

Fig. (13): Discrete Input and Output 


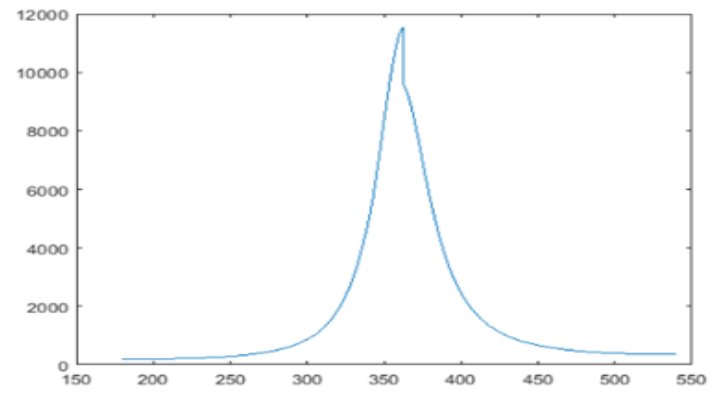

Fig. (14): Pressure Distribution Versus CA

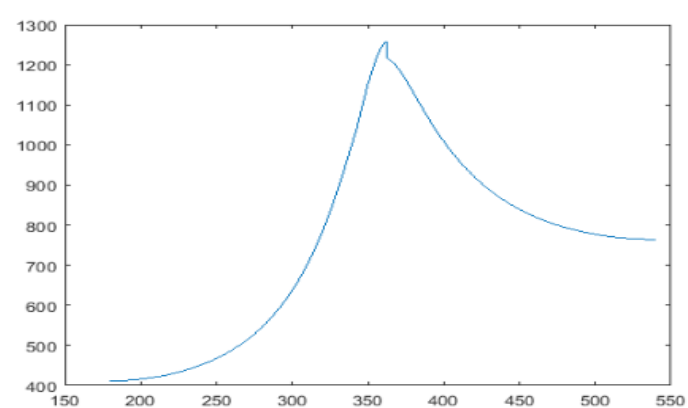

Fig. (15): Temperature Distribution Versus CA

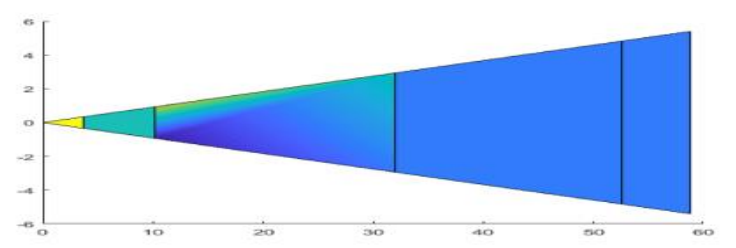

Fig. (16): Penetration Length in Matlab Model

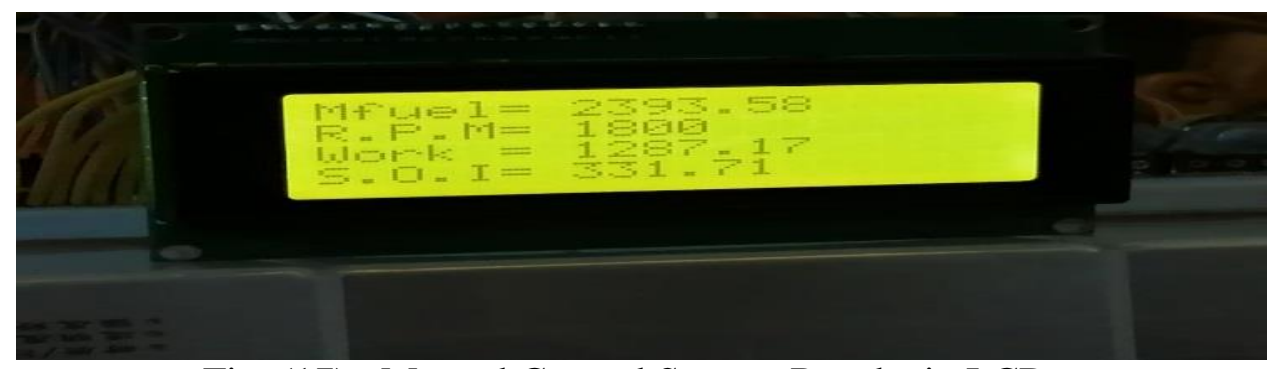

Fig. (17) : Manual Control System Results in LCD

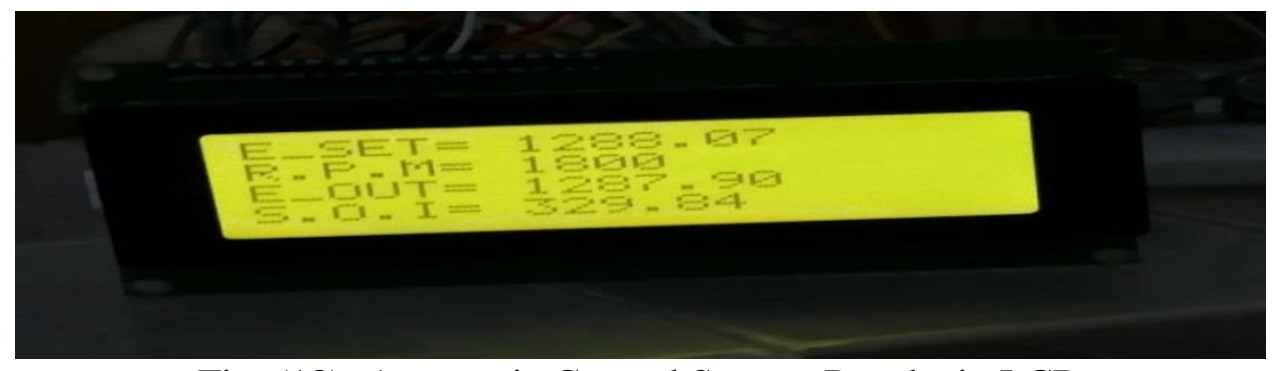

Fig. (18): Automatic Control System Results in LCD 


\section{REFERENCES}

Arduino, S. A. (2015). "Arduino." Arduino LLC.

Barber, R., et al. (2013). "Control practices using simulink with arduino as low cost hardware." IFAC Proceedings Volumes 46(17): 250-255.

Baykara, C., et al. (2017). "Skip cycle method with a valve-control mechanism for spark ignition engines." Energy conversion and management 146: 134-146.

Bracco, F. (1985). Modeling of engine sprays, SAE Technical Paper.

Breitzman, R. (1985). "Development of a custom microprocessor for automotive control." IEEE Control Systems Magazine 5(2): 23-28.

Egüz, U. (2013). Crossing the combustion modes in diesel engines, $\mathrm{PhD}$ thesis, Combustion Technology, Eindhoven University of Technology. Cited on.

El Wakil, M. M., et al. (1956). Fuel Vaporization and Ignition Las in Diesel Combustion, SAE Technical Paper.

Ferguson, C. R. and A. T. Kirkpatrick (2015). Internal combustion engines: applied thermosciences, John Wiley \& Sons.

Gonzalez, E. G., et al. (2008). "Development of the management strategies of the ECU for an internal combustion engine: computer simulation." Mechanical Systems and Signal Processing 22(6): 1356-1373.

Han, M. and B. Lee (2015). "Control oriented model of a lean NOx trap for the catalyst regeneration in a $2.2 \mathrm{~L}$ direct injection diesel engine." International Journal of Automotive Technology 16(3): 371-378.

Heywood, J. B. (1988). "Internal combustion engine fundamentals."

Johnson, D. V., et al. (2016). Development of Electrical-Electronic Controls for a Gasoline Direct Injection Compression Ignition Engine, SAE Technical Paper.

Jung, D. and D. N. Assanis (2001). "Multi-zone DI diesel spray combustion model for cycle simulation studies of engine performance and emissions." SAE Transactions: 1510-1532.

Kuo, K. K. (1986). "Principles of Combustion John Wiley \& Sons." New York.

Lanský, L. (2008). Diesel engine modelling and control, Master's thesis. Department of Control Engineering, Faculty of Electrical ....

Lefebvre, A. (1989). "Atomization and Sprays"Hemisphere Publishing Corp." New York. 
Morgan, R., et al. (2001). "The influence of injector parameters on the formation and breakup of a diesel spray." SAE Transactions: 389-399.

Nishida, K. and H. Hiroyasu (1989). "Simplified three-dimensional modeling of mixture formation and combustion in a DI diesel engine." SAE transactions: 276-293.

Oskam, G. (2014). "Optimizing diesel engine condition monitoring: Research on diagnostic representation techniques based on in-cylinder pressure measurement."

Peyton Jones, J. and K. Muske (2007). "Automatic calibration of 1 and 2-d look-up tables using recursive least-squares identification techniques." Electronic Engine Controls(2007-01): 1343.

Qi, K.-p., et al. (2010). "Simulation of quasi-dimensional model for diesel engine working process." Journal of Central South University of Technology 17(4): 868-872.

Raeie, N., et al. (2014). "Effects of injection timing, before and after top dead center on the propulsion and power in a diesel engine." Propulsion and power research 3(2): 59-67.

Siebers, D. L. (1999). "Scaling liquid-phase fuel penetration in diesel sprays based on mixinglimited vaporization." SAE transactions: 703-728.

Slepicka, C. and C. R. Koch (2016). "Iterative Learning on Dual-fuel Control of Homogeneous Charge Compression Ignition." IFAC-PapersOnLine 49(11): 347-352.

Thring, M. and M. Newby (1953). Combustion length of enclosed turbulent jet flames. Symposium (International) on Combustion, Elsevier.

Triwiyatno, A., et al. (2015). Smart controller design of air to fuel ratio (AFR) and brake control system on gasoline engine. 2015 2nd International Conference on Information Technology, Computer, and Electrical Engineering (ICITACEE), IEEE.

Turns, S. R. (1996). An introduction to combustion, McGraw-Hill New York.

Vijay, E. V., et al. (2010). Electronic control unit for an adaptive cruise control system \& engine management system in a vehicle using electronic fuel injection. INTERACT-2010, IEEE.

Watson, N., et al. (1980). A combustion correlation for diesel engine simulation, SAE Technical Paper.

Zulkifli, S. A., et al. (2015). "MATLAB-Simulink Controller Design For Arduino Target On Ac Motor Control Application." Inter. Journal. Eng. Power Engineering Research. 